\title{
Inhibition of the Soluble Epoxide Hydrolase as an Analgesic Strategy: A Review of Preclinical Evidence
}

This article was published in the following Dove Press journal: Journal of Pain Research

\author{
Yuxin Wang \\ Karen M Wagner \\ Christophe Morisseau (D) \\ Bruce D Hammock \\ Department of Entomology and \\ Nematology, UC Davis Comprehensive \\ Cancer Center, University of California \\ Davis, Davis, CA 95616, USA
}

\begin{abstract}
Chronic pain is a complicated condition which causes substantial physical, emotional, and financial impacts on individuals and society. However, due to high cost, lack of efficacy and safety problems, current treatments are insufficient. There is a clear unmet medical need for safe, nonaddictive and effective therapies in the management of pain. Epoxy-fatty acids (EpFAs), which are natural signaling molecules, play key roles in mediation of both inflammatory and neuropathic pain sensation. However, their molecular mechanisms of action remain largely unknown. Soluble epoxide hydrolase (sEH) rapidly converts EpFAs into less bioactive fatty acid diols in vivo; therefore, inhibition of sEH is an emerging therapeutic target to enhance the beneficial effect of natural EpFAs. In this review, we will discuss sEH inhibition as an analgesic strategy for pain management and the underlying molecular mechanisms.
\end{abstract}

Keywords: epoxy fatty acids, chronic pain, molecular mechanisms

\section{Introduction}

Pain is a critical signal and a survival mechanism, but enhanced and persistent pain is an unpleasant sensation and emotional experience which has a profound impact on individuals and society. ${ }^{1,2}$ There are approximately 100 million Americans suffering from chronic pain, with an associated \$560-635 billion yearly cost in direct medical expenses and lost productivity. ${ }^{3}$ In 2016 , approximately $20 \%$ of US adults had chronic pain (approximately 50 million), and $8 \%$ of US adults (approximately 20 million) had high-impact chronic pain according to the Centers of Disease Control and Prevention (CDC). ${ }^{4}$ Opioids are major pharmaceutical treatments available to control pain; however, they have serious side effects, leading to increasing risks for abuse and overdose-related deaths. ${ }^{5}$ We need additional analgesic agents that can be integrated into multimodal pain control strategies. ${ }^{6}$ Therefore, pain management research has become one of the top priorities in the US and developing new therapeutic approaches for pain management that are both effective and safe is practically important for our society.

The natural purpose of pain is to protect body from damage or potentially damaging situation. ${ }^{7}$ However, chronic pain is not always related to tissue damage and does not always serve a protective function. ${ }^{8}$ Based on the biological and physiological processes involved, pain is classified as either nociceptive, neuropathic, or inflammatory. ${ }^{9}$ Nociceptive pain can be triggered by exposure to extreme
Correspondence: Bruce D Hammock Email bdhammock@ucdavis.edu
Journal of Pain Research 2021:14 61-72

(c) (i) (\$) ๑ 202I Wang et al. This work is published and licensed by Dove Medical Press Limited. The full terms of this license are available at https://www.dovepress.com/terms. cc) work you herbby accept the Terms. Non-commercial uses of the work are permitted without any further permission from Dove Medical Press Limited, provided the work is properly attributed. For permission for commercial use of this work, please see paragraphs 4.2 and 5 of our Terms (https://www.dovepress.com/terms.php). 
heat, cold or noxious pressure. ${ }^{10}$ Neuropathic pain, which is caused by a lesion or disease of the somatosensory nervous system may occur spontaneously in the absence of stimuli or be evoked by sensory stimuli inducing hyperalgesia and allodynia. ${ }^{11}$ Inflammation is characterized by redness, heat, swelling, pain or hypersensitivity, and loss of function usually occurs subsequent to injury and involves the release of cytokines and immune cell infiltration. ${ }^{12}$ Since different forms of pain involve a variety of distinct biological processes, a better understanding of the molecular mechanisms underlying the pain is key for the development of more effective and safe therapies in the near future.

Eicosanoids are the metabolites of arachidonic acid (ARA) and related unsaturated fatty acids produced by three oxidative pathways, cyclooxygenase (COX), lipoxygenase (LOX), and cytochrome P450 (CYP450). They are important lipid signaling molecules involved notably in the regulation of inflammation and pain. ${ }^{13-15}$ While the COX and LOX pathways are well studied, the CYP450 is less understood and is at the center of this review. In this pathway, polyunsaturated fatty acids (PUFAs) including linoleic acid (LA), $\alpha$-linolenic acid (ALA), dihomo- $\gamma$-linolenic acid (DGLA), arachidonic acid (ARA), eicosapentaenoic acid
(EPA), docosahexaenoic acid (DHA), and others are metabolized by CYP monooxygenases, especially CYP2C and CYP2J isoforms, to form a mixture of monohydroxy-fatty acids (hydroxyeicosatetraenoic acids (HETEs) from ARA) and epoxy-fatty acids (EpFAs; such as epoxy-eicosatrienoic acids (EETs) from ARA) with diverse biological actions, especially in inflammatory related diseases (Figure 1). ${ }^{13,16-}$ ${ }^{18}$ In this review, we will discuss the roles of CYP450 and their metabolites in the pathology of chronic pain and the underlying mechanisms of action of these metabolites.

\section{Soluble Epoxide Hydrolase and Pain The Effect of Epoxy-fatty Acids in Pain Model}

The EpFAs, especially EETs, which function primarily as both autocrine and paracrine signaling molecules, have well described beneficial effects on multiple cardiovascular diseases, the renal system, angiogenesis, inflammation, and cancer. ${ }^{19-21}$ Using an animal model of inflammatory pain, the total oxylipin concentrations were measured both in the spinal cord and brain of rats after base hydrolysis of the lipid esters. EpFAs, especially from ARA and DHA, but neither the parent fatty acid nor the corresponding
A

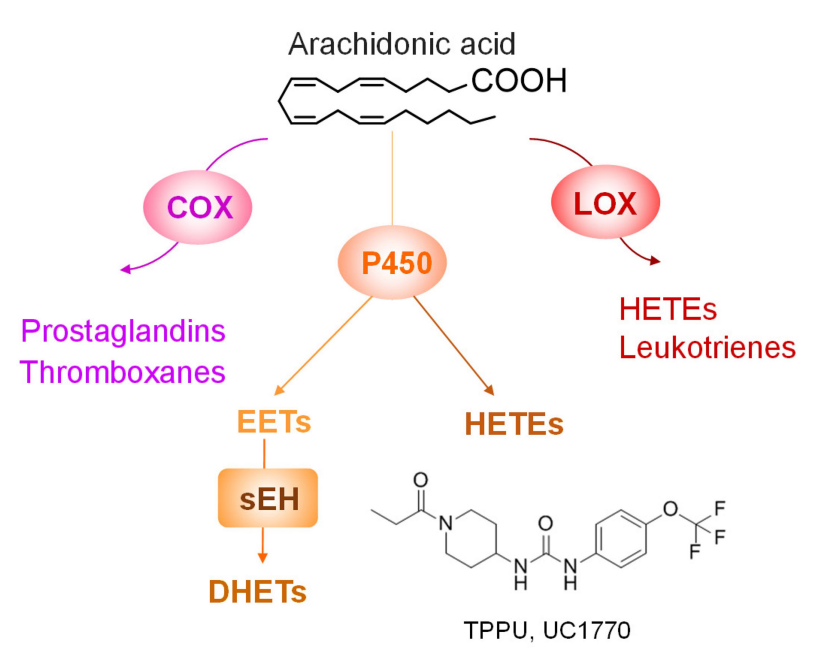

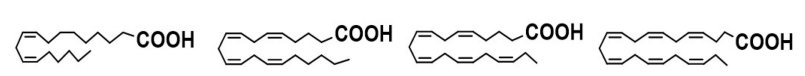

LA

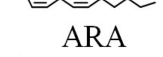

EPA

DHA
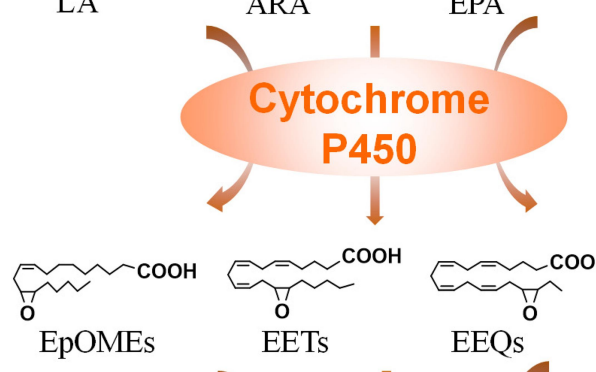

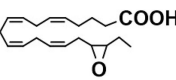

EEQs

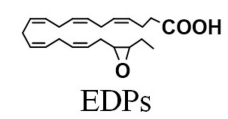

EpOMEs

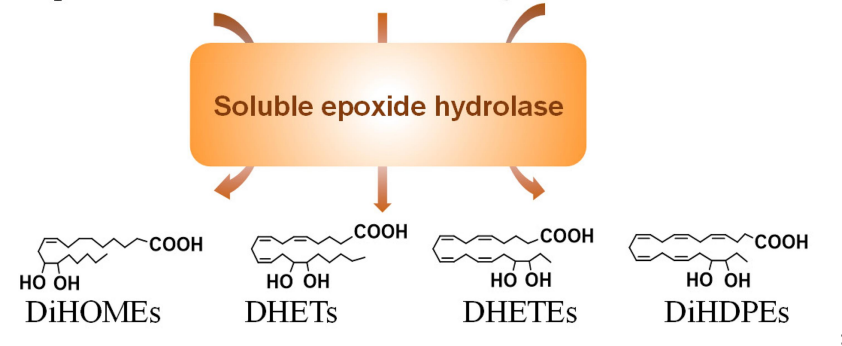

1

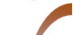

DHETs

Figure I (A) Metabolism of ARA by COX, LOX, and CYP enzymes leads to formation of oxylipin metabolites. The structure of the sEHI TPPU is shown. (B) The CYP/sEH pathway that produces epoxy-fatty acids and corresponding diols. For simplicity, only one regioisomer of the epoxides and diols are shown here.

Abbreviations: ARA, arachidonic acid; COX, cyclooxygenase; LOX, lipoxygenase; CYP, cytochromes P450; EETs, epoxyeicosatrienoic acid; HETEs, hydroxyeicosatetraenoic acids; DHETs, dihydroxy-eicosatrienoic acids; LA, linoleic acid; EPA, eicosapentaenoic acid; DHA, docosahexaenoic acid; EpOMEs, epoxy-octadecenoic acid; EEQs, epoxy-eicosatetraenoic acid; EDPs, epoxy-docosapentaenoic acid; DiHOMEs, dihydroxy-octadecenoic acid; DiHETEs, dihydroxyicosa-tetraenoic acid; DiHDPEs, dihydroxydocosapentaenoic acid. 
diols, selectively modulate nociceptive pathophysiology, and spinal administration of epoxy-docosapentaenoic acids (EpDPE) reduces both mechanical and thermal pains associated with inflammation, supporting an important function of EpFAs in modulating nociceptive signaling. ${ }^{22}$ Additional studies showed that EpFAs are effective in both inflammatory and neuropathic pain models, suggesting them as potential novel therapeutics for pain management. ${ }^{23-25}$ However, in vivo, the EpFAs are rapidly metabolized by soluble epoxide hydrolase ( $\mathrm{sEH}$ ) to generate the corresponding and less-bioactive, even proinflammatory, dihydroxy-eicosatrienoic acids (DHETs) (Figure 1B) ${ }^{26-29}$ Therefore, sEH inhibitors (sEHIs) were developed to increase in vivo EpFAs levels, and thus reduce blood pressure, improve insulin sensitivity, and decrease inflammation. ${ }^{28,30-33}$ The $\mathrm{sEH}$ is considered an emerging therapeutic target for enhancing the beneficial function of EpFAs in numerous diseases, including cardiovascular diseases, inflammatory bowel diseases, hypertension, and metabolic disorders, which have inflammation as a common underlying cause. ${ }^{28,30-33}$

\section{The Effect of sEHIs in Pain Model}

In an inflammatory pain model induced with intraplantar injection of $10 \mu \mathrm{g}$ lipopolysaccharides (LPS) in one hind paw of rats, using an sEHI 1-trifluoromethoxyphenyl-3-(1acetylpiperidin-4-yl)-urea (TPAU) through intraplantar injection significantly blocked inflammatory pain in a dose-dependent manner. ${ }^{24}$ Moreover, an sEH metabolite 12,13-dihydroxy-9Z-octadecenoic acid (12,13-DiHOME) was increased in peripheral nervous tissue during acute zymosan- and complete Freund's adjuvant (CFA)-induced inflammatory pain. ${ }^{34}$ In this CFA-induced inflammatory pain model, oral administration of 1-trifluoromethoxyphenyl-3-(1-propionylpiperidin-4-yl (TPPU) reduces 12.13DiHOME concentrations and reduces zymosan- and CFA-induced thermal hyperalgesia in vivo. ${ }^{34}$ These results showed the analgesia effect of sEHIs in inflammatory pain. In addition, compared to the traditional nonsteroidal antiinflammatory drug celecoxib, sEHIs are superior and have better efficacy in both diabetic neuropathy and inflammatory pain models. ${ }^{35}$

Wagner et al. demonstrated that compared with gabapentin, subcutaneously injection of the sEHI trans-4-[4-(3trifluoromethoxyphenyl-1-ureido)-cyclohexyloxy]-benzoic acid ( $t$-TUCB) elicited a similar degree of withdrawal threshold improvement without the same degree of spontaneous locomotion decline in mice with neuropathic pain. ${ }^{36}$ In diabetic Akita mice (Ins2Akita or Ins2C96Y), which progress naturally and are more similar to the human disease state than chemical ablation of beta islet cells. The results showed $t$-TUCB is an analgesic in diabetic neuropathy, and this effect is related to sexual dimorphism since the female mice are less susceptible to the diabetic phenotype. ${ }^{37}$ These results indicate the sEHI has analgesic effects with limited side effects in diabetic neuropathy pain.

\section{Synergistic Effect of $s E H I$ with Other Pharmaceutical Inhibitors in Pain}

Besides potent effects from sEHI itself, recent research showed combinations of sEHI and other enzyme inhibitors might achieve greater analgesic efficacy therapeutically. For example, the combination treatment of nonsteroidal antiinflammatory drugs (NSAIDs) and the sEHI 12-(3-adamantan-1-yl-ureido)dodecanoic acid $n$-butyl ester (AUDA-nBE) produced significantly beneficial effects for alleviating LPSinduced inflammatory pain in mice. ${ }^{38}$ The NSAIDs and SEHI combination therapy also reduced COX-2 protein expression and shifted oxylipin metabolomic profiles, ${ }^{38}$ suggesting that this therapy has efficacy in decreasing inflammation but also decreased side effects of NSAIDs in cardiovascular and gastrointestinal tract complications. ${ }^{38-40} \mathrm{~A}$ COX-2/sEH dual inhibitor, 4-(5-phenyl-3-\{3-[3-(4-trifluoromethylphenyl)-ureido]-propyl\}-pyrazol-1-yl)-benzenesulfonamide (PTUPB) exhibited antiallodynic activity that was more effective than the same dose of either a COX-2 inhibitor (celecoxib) or a sEH inhibitor $t$-AUCB alone, as well as coadministration of both inhibitors in a nociceptive behavioral assay. ${ }^{41}$ In addition, fatty acid amide hydrolase (FAAH) is another enzyme catalyzing the hydrolysis of bioactive lipid mediators - fatty acid ethanolamides (FAEs). Previous results demonstrated combinations of a sEHI, TPPU, and FAAH inhibitor, URB937, showed high antihyperalgesia activity in two pain models: carrageenan-induced hyperalgesia in mice and streptozocin-induced allodynia in rats, revealing a possible functional crosstalk between FAEs and EpFAs in regulating pain responses. ${ }^{42}$ Moreover, phosphodiesterase-4 (PDE-4)-targeted therapies have shown promise for treating patients with a variety of autoimmune diseases. ${ }^{43}$ Co-inhibition of sEH and PDE-4, greatly increases the level of EpFAs and is thus more efficient at reducing acute pain perception. ${ }^{44}$ A novel PDE-4/sEH dual inhibitor $N$-(4-methoxy-2-(trifluoromethyl)benzyl)-1-propionylpiperidine-4-carboxamide (MPPA) at $3 \mathrm{mg} / \mathrm{kg}$ (oral administration) reduced 
LPS-induced inflammatory pain. MPPA also does not alter self-motivated exploration of rats with inflammatory pain or the withdrawal latency in control rats, suggesting that MPPA has good efficacy together with limited off-target effects. ${ }^{45}$

\section{The Underlying Mechanisms of sEHI/EpFAs in Pain Management Cyclic Adenosine Monophosphate (cAMP) Signaling Pathway in Pain}

Cyclic adenosine 3',5'-monophosphate (cAMP) was the first identified second messenger and plays a fundamental role in many cellular responses to hormones and neurotransmitters. ${ }^{46-48}$ The intracellular levels of cAMP are regulated by the balance between two enzymes: adenylyl cyclase (AC), which catalyzes cAMP formation from ATP, ${ }^{49}$ and cyclic nucleotide phosphodiesterase (PDE) that degrades intracellular cyclic nucleotides. ${ }^{50}$ PDE inhibitors have been shown as therapeutic approach to neuroprotection, repair, and cardiovascular system. ${ }^{51,52}$ Rolipram, a selective PDE-4 inhibitor and theophylline, a nonspecific PDE inhibitor exerted dose-dependent analgesic and antiinflammatory effect against acetic acid-induced writhing in mice and carrageenan-induced paw edema in rats. ${ }^{53}$
Rolipram induced artificially elevated cAMP in healthy mice, while co-administration with the sEHI 1-trifluoromethoxyphenyl-3-(1-acetylpiperidin-4-yl) urea (TPAU) largely blunted pain-related behavior, which indicate the analgesic effect of sEH inhibitor and PDE-4 inhibitor. ${ }^{44}$ These results indicate the analgesic effect of sEHIs is dependent on cAMP. In another study, EETs or sEHI lead to antihyperalgesia and was correlated to upregulation of, steroidogenic acute regulatory protein (StARD1), a carrier protein which assists neuro-steroid production. ${ }^{54}$ In summary, these results further give mechanistic evidence showing the analgesic effect of sEHIs through cAMP signaling pathway (Figure 2).

\section{PPARs Signaling in Pain}

Peroxisome proliferator-activated receptors (PPARs) are ligand-activated transcription factors belonging to a nuclear hormone receptor superfamily, which contains three isoforms: PPAR $\alpha$, PPAR $\beta / \delta$ and PPAR $\gamma .{ }^{55,56}$ The three PPARs share a high homology but differ in tissue distribution and ligand specificity. ${ }^{57}$ PPARs primary function as important fatty acid sensors which not only regulate lipid, carbohydrates, and amino acid metabolism, but also play key roles in various pathophysiology processes. ${ }^{55}$ Extensive research showed PPARs may also involve in the control of the

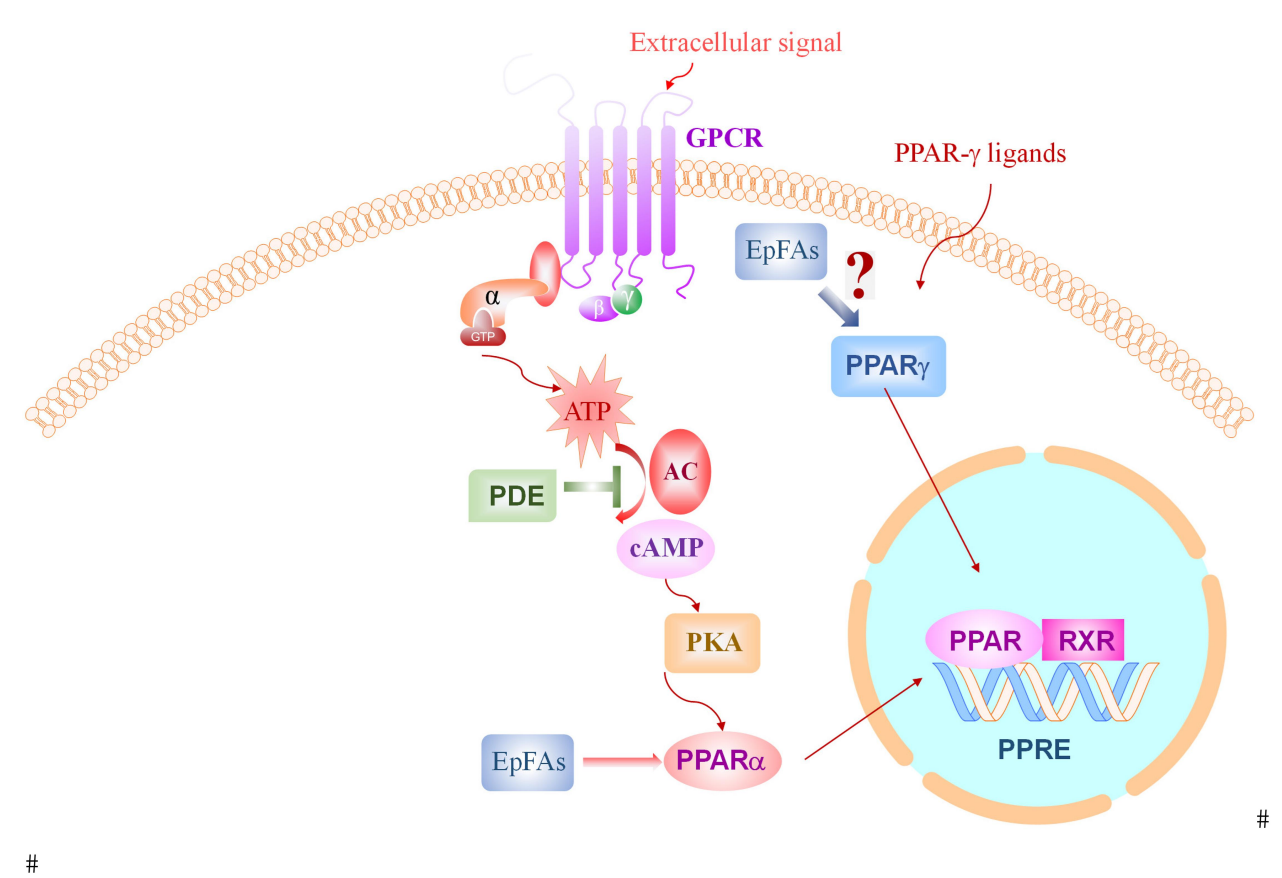

Figure 2 The effect of $s E H$ inhibition and EpFAs on cAMP-PPAR signaling pathways.

Abbreviations: GPCR, G-protein-coupled receptors; PPAR, peroxisome proliferator-activated receptor gamma; EpFAs, epoxy fatty acids; ATP, adenosine triphosphate; cAMP, cyclic adenosine monophosphate; PKA, protein kinase A; PDE, phosphodiesterase; RXR, retinoid X receptor; PPRE, peroxisome proliferator hormone response elements. 
nociceptive response and neuropathic pain. ${ }^{58,59}$ There is evidence showing cAMP is the major stimulator of PPAR activity and cAMP signaling pathway modulates PPAR function, possibly by transactivation, ${ }^{60,61}$ suggesting the link between cAMP and PPAR signaling pathways. Interestingly PPAR agonists are potent inducers of the $\mathrm{SEH}$ message and protein.

A relevant study on PPARs and pain investigated the activation of PPAR in the rat spinal cord following subcutaneous injection of CFA into a hind paw. ${ }^{62}$ The results showed only the PPAR $\alpha$ isoform was activated using electrophoretic mobility-shift assay (EMSA) method. LoVerme et al. showed in mice that PPAR $\alpha$ agonists suppress pain behaviors induced by tissue injury, nerve damage, or inflammation. ${ }^{63}$ In addition, PPAR $\alpha^{-1-}$ female mice are hypersensitive to the cold, mechanical allodynia, and heat hyperalgesia, ${ }^{64}$ suggesting genetic ablation of PPAR $\alpha$ is involved in neuropathic and visceral nociception. ${ }^{64}$ Leukotriene $\mathrm{B}_{4}$, a potent agent that initiates, coordinates, and amplifies the inflammatory response, is an activating ligand for the transcription factor PPAR $\alpha .{ }^{65}$ These results suggest the critical role of PPAR $\alpha$ in the control of nociception and inflammation. Thus, further studies of combined effects on sEHI and PPAR $\alpha$ agonist in pain preclinical models are needed and development of this novel class of compounds could represent a useful new pharmacological approach for the pain relief.

PPAR $\gamma$ is another subtype of PPAR, which is present in several tissues and cell types. ${ }^{66}$ Intrathecally administered PPAR $\gamma$ agonists dose-dependently decreased mechanical and cold hypersensitivity in the rats, ${ }^{58}$ demonstrating the important role of PPAR $\gamma$ in the neuropathic pain. Further studies demonstrated that activation of PPAR $\gamma$ has beneficial effects of modification of astrocyte metabolism and mitochondrial function which are important in inflammation. ${ }^{67,68}$ In addition, the PPAR $\gamma$ agonist, rosiglitazone, attenuated CFA-induced inflammatory pain through induction of heme oxygenase (HO)-1, leading to the differentiation of pro-inflammatory M1 macrophages to anti-inflammatory M2 phenotype ${ }^{69}$ In an angiotensin-II (AngII) induced cardiac hypertrophy model, sEH is upregulated by AngII. Rosiglitazone is a potent sEH inducer and the protective role of PPAR $\gamma$ activation in AngIIinduced cardiac hypertrophy is partially through downregulating sEH. ${ }^{70,71}$ Thus, the beneficial actions of rosiglitazone should be enhanced and some of its side effects reduced by co-administration with sEHI since the combined administration of both pharmacological agents rosiglitazone and the sEH inhibitor $t$-AUCB led to synergistic improvement of vascular function and reduced fibrotic kidney damage. ${ }^{72}$

EETs, together with the sEHI 12-(3-adamantan-1-ylureido) dodecanoic acid (AUDA), increased PPAR $\gamma$ transcription activity in endothelial cells and 3T3-L1 preadipocytes and PPAR $\gamma$ antagonist GW9662 abolished the EET/AUDA-mediated anti-inflammatory effect, indicating PPAR $\gamma$ is an effector of EETs. ${ }^{73}$ Further study demonstrated that dual PPAR $\gamma / \mathrm{sEH}$ inhibitor RB394 showed the ability to blunt diabetic complications such as hypertension, insulin resistance, hyperlipidemia, and kidney injury in metabolic syndrome modeled in obese spontaneously hypertensive (SHROB) rats and obese diabetic Zucker fatty/spontaneously hypertensive heart failure F1 hybrid (ZSF1) rats. ${ }^{74}$ Another study showed the dual inhibitor RB394 or combination of sEHI and PPAR $\gamma$ agonist significantly prevented renal fibrosis development by preventing renal inflammation and oxidative stress. ${ }^{75}$ Interestingly the sEHI will of course counter the sEHI induction and other possible deleterious side effects of high dose PPAR $\gamma$ agonists. $^{76} \mathrm{Kim}$ et al. demonstrated that SEHI $t$-TUCB could promote anti-inflammatory effects in ureteral obstruction in mice, the mechanism is mainly through increased levels of EETs and inhibition the PPAR $\gamma$ reduction. ${ }^{77}$ Altogether, these results indicate that PPAR $\gamma$ is an important effector in the anti-inflammatory effect of sEHI, while more evidence is still needed for the mechanism study of sEHI in the pain management through PPAR signaling pathways (Figure 2).

\section{The Transient Receptor Potential (TRP) Superfamily in Pain}

The superfamily of TRP channels play critical roles in the responses to the major classes of external stimuli, including light, sound, chemicals, temperature, and touch. ${ }^{78}$ Mutations in several TRP genes have been implicated in pain pathological states. ${ }^{79}$ Most TRPs are nonselective cation channels, only a few are highly $\mathrm{Ca}^{2+}$ selective, or permeable for highly hydrated $\mathrm{Mg}^{2+}$ ions. ${ }^{79}$

Transient receptor potential ankyrin 1 (TRPA1) is the most well-studied pain regulator among TRP superfamily, which is one of the $\mathrm{Ca}^{2+}$-permeable cation ion channels involved in the transduction of potentially harmful stimuli and in amplification of nociceptive transmission in their central terminals. ${ }^{80-83}$ Studies revealed TRPA1 is a potential target in pain relief. A TRPA1 selective antagonist significantly reduced mechanical hyperalgesia evaluated 
by the von Frey assay and completely inhibited the noxious cold hyperalgesia in CFA induced persistent inflammation in mice. ${ }^{80}$ Furthermore, TRPA1 also plays key roles in the inflammatory pain, neuropathic pain and migraine. ${ }^{84}$ Both genetic deletion of Trpal and pharmacological inhibition of TRPA1 abrogated pain-like behaviors in mice. $^{85}$

In addition to TRPA1, transient receptor potential cation channel subfamily V member 1 (TRPV1) is another $\mathrm{Ca}^{2+}$ permeant nonselective member of TRP family which has been implicated in a variety of cellular and physiological processes, including noxious physical and chemical stimuli detection, making it one of the promising targets for painrelieving drugs. ${ }^{86,87} \mathrm{TRPV}^{-/-}$mice showed no vanilloidevoked pain behavior in the detection of painful heat and showed little thermal hypersensitivity in the inflammation, and TRPV $1^{-/}$mice showed an attenuated fever in response to LPS. ${ }^{88,89}$ These results conclude TRPV1 is essential in the inflammatory thermal hyperalgesia, nociception, and pain sensation. Finally, several TRPV1 agonists such as JNJ-39,439,335, NEO6860, and ABT-102 have been in clinical trials targeting pain relief. ${ }^{90-92}$ Altogether, these results suggest examination of TRPV1 as a mechanistic target for pain treatment.

sEH was shown to regulate pain via TRP channels. The sEH enzyme has been reported as co-localized with TRPV1 in the primary trigeminal ganglion neurons (TGNs). ${ }^{93}$ Pretreatment with $10 \mu \mathrm{M}$ EETs antagonist 14.15-epoxyeicosa-5(Z)-enoic acid (14,15-EEZE) attenuated the calcitonin gene-related peptide (CGRP) release, which is a marker of neurogenic inflammation. ${ }^{93}$ The CGRP release is induced by TRPV1 agonist capsaicin or $\mathrm{K}^{+}$, but sEHI AUDA did not have this effect, ${ }^{93}$ suggesting that there are inadequate levels of EETs released to be stabilized by AUDA. These data suggest EETs may act as intracellular regulators of neuropeptide release, which may have important clinical implications for treatment of neurogenic inflammation. Further investigation into the therapeutic potential of sEHI through TRP channels is needed.

\section{Endoplasmic Reticulum (ER) Stress Signaling Pathway in Pain}

The endoplasmic reticulum (ER) is an organelle in which newly synthesized secretory and transmembrane proteins are assembled and folded into their correct tertiary structures. ${ }^{94}$ However, protein misfolding caused by various stimuli and gene mutations, leads to the disruption of
ER function and activation of ER stress signaling pathway. Eukaryotic cells have developed an evolutionarily conserved adaptive mechanism called unfolded protein response (UPR), whose purpose is to clear unfolded proteins, promote proper folding by increased chaperones and reduced protein synthesis, and restore ER homeostasis. ${ }^{95}$ The UPR influences cellular metabolism through diverse mechanisms, including calcium and lipid transfer, which are key involvement in the pathogenesis of diseases, including pain, neurodegeneration, and cardiovascular disease. $^{96-98}$ When unfolded proteins accumulate in the $\mathrm{ER}$, the N-terminus in the lumen of the ER chaperone Grp78 releases transmembrane ER proteins involved in inducing the UPR to prevent their aggregation. However, when misfolded proteins accumulate, Grp78 releases, allowing aggregation of these transmembrane signaling proteins, launching and activating the UPR. ${ }^{99}$ The UPR is distinguished by the action of three signaling proteins named IRE1 $\alpha$ (inositol-requiring protein-1 $\alpha$ ), PERK (protein kinase RNA (PKR)-like ER kinase), and ATF6 (activating transcription factor 6$).{ }^{95}$

The ER stress signaling pathway has been demonstrated as playing key roles in the pathogenesis of pain. The IRE1 $\alpha$-unspliced X-box-binding protein 1 (XBP1) axis operates as a crucial mediator of eicosanoid metabolism and prostaglandin synthesis in myeloid immune cells by promoting the expression of both COX-2 and microsomal prostaglandin E synthase-1 (mPGES-1), and genetic ablation or pharmacological inhibition of this pathway diminishes pain-related behaviors in mice. ${ }^{100}$ Other research showed that an IRE1 $\alpha$ small interfering RNA (siRNA) improved the neurological morphology and reduced diabetic peripheral neuropathy (DPN) in rats. ${ }^{101}$ It also rescued ER stress-related apoptosis in the sciatic nerve, ${ }^{101}$ indicating IRE1 $\alpha-$ XBP1 signaling may be helpful for the improvement of pain management. In addition, Lupachyk et al. examined the role of ER stress signaling in the development of peripheral neuropathy in streptozotocin (STZ)-induced diabetic rodents and found two structurally dissimilar chemical chaperones (trimethylamine oxide [TMAO] and 4-phenylbutyric acid [4-PBA]), which can counteract ER stress by promoting normal protein folding, significantly suppressed ER stress marker proteins whose upregulation was induced by STZ, ${ }^{102,103}$ reduced thermal and mechanical responses, and enhanced sensitivity to touch with diabetes. ${ }^{103}$ They also observed the neuropathic effects of CCAAT-enhancer-binding proteins $(\mathrm{C} / \mathrm{EBP})$ homologous protein $(\mathrm{CHOP})$, one of the 
components of the ER stress-mediated apoptosis pathway in the DPN. ${ }^{104}$ The results showed genetic ablation of CHOP showed attenuation of motor and sensory nerve conduction velocity deficits, thermal hypoalgesia, and intraepidermal nerve fiber loss, while diabetes-induced mechanical hypoalgesia and tactile allodynia remained at similar levels in both $\mathrm{CHOP}^{-/-}$and wild-type mice, ${ }^{102}$ suggesting different aspects of ER stress and the UPR were targeted in diabetic neuropathy.

Numerous studies showed sEH is a physiological modulator of ER stress signaling involved in many disorders. ${ }^{105-107}$ Thus, the sEH enzyme is a nonchannel, non-neurotransmitter therapeutic and well characterized target for pain. ${ }^{108}$ Both pain and ER stress markers are elevated in peripheral nervous system of type I diabetic rats. Further results showed TPPU, a widely used potent sEH inhibitor, blocks pain-related behavior and suppresses markers of the ER stress signaling pathway (p-PERK, p-IRE1 $\alpha$, and cleaved-ATF6). ${ }^{108,109}$ In addition, TPPU reversed the tunicamycin (Tm) induced ER stress response and pain-related behaviors both alone and synergistically together with chemical chaperon 4-PBA. ${ }^{108}$ This observation suggests a beneficial drug interaction among chemical chaperones and sEHI. Another sEHI $t$-TUCB, attenuated neuropathic pain without the same degree of spontaneous locomotion that is observed with gabapentin. ${ }^{36}$ Altogether, these results indicate dosing with sEHI represents an analgesic strategy for pain relief through the ER stress signaling pathway (Figure 3).

\section{Interaction and Complementarities of the Three Mechanistic Pathways}

There is evidence showing an interaction among cAMPPPAR, TRP channels and ER stress signaling pathways. These include ER stress regulated uncoupling protein 1 (UCP1) expression via PPAR $\gamma$ suppression in beige adipocytes, ${ }^{110}$ and UCP1 increased by both PPAR $\gamma$ stimulation and cAMP activation through their ability to stimulate the expression of the peroxisome proliferator-activated receptor gamma coactivator 1 -alpha $(\mathrm{PGC} 1 \alpha) .{ }^{111} \mathrm{In} \mathrm{Zn}$ induced lipolysis, Zn exposure evoked ER stress and dysregulation of $\mathrm{Ca}^{2+}$ homeostasis, and then activated cAMP/ protein kinase A (PKA) pathway resulting in hepatic lipolysis, ${ }^{112}$ highlighting the importance of the ER stress-cAMP/PKA axis in Zn-induced lipolysis.

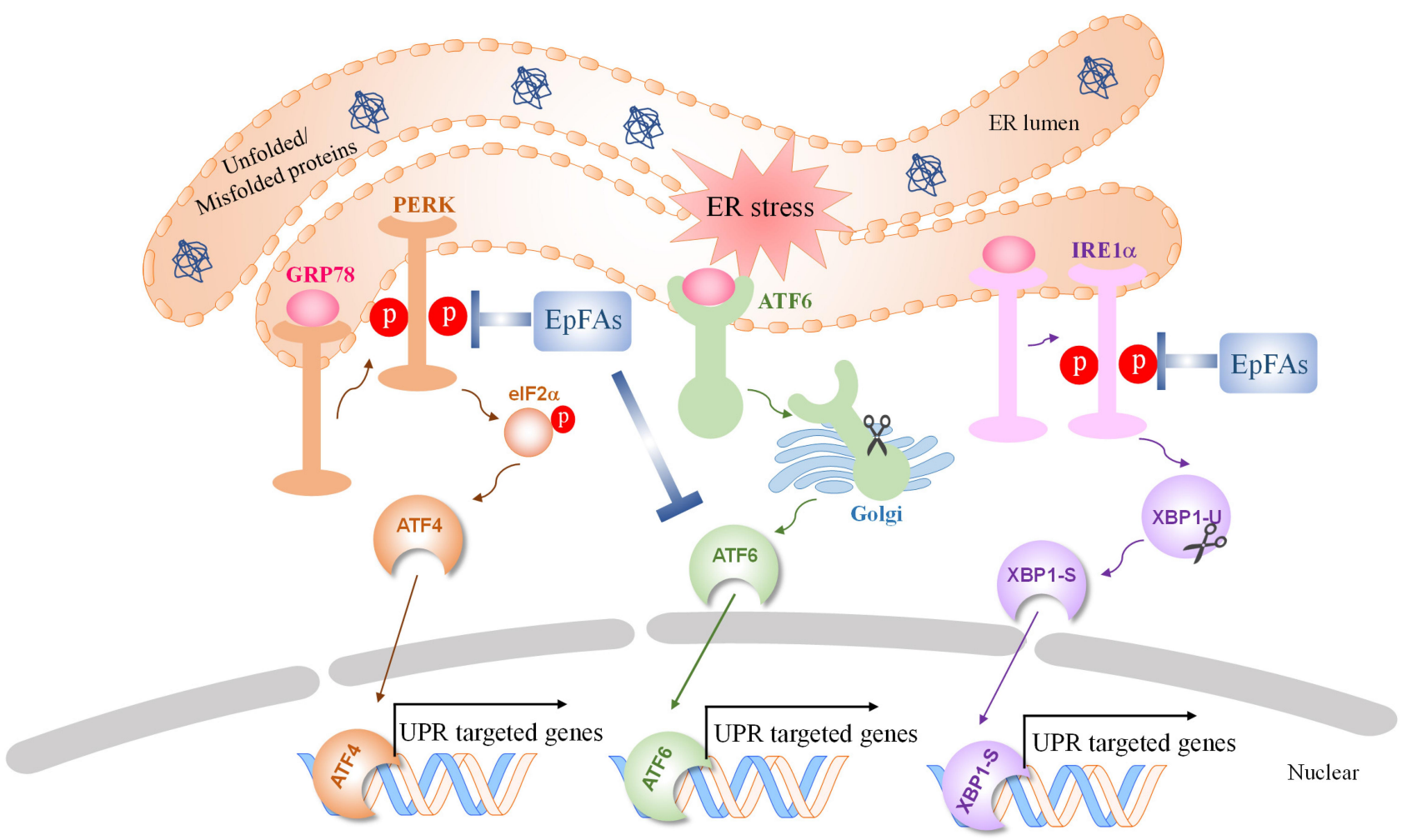

Figure 3 The effect of sEH inhibition and EpFAs on Endoplasmic Reticulum (ER) stress signaling pathways.

Abbreviations: ER, endoplasmic reticulum; PERK, protein kinase R (PKR)-like endoplasmic reticulum kinase; GRP78, glucose-regulated protein; elF2 $\alpha$, eukaryotic initiation factor 2 $\alpha$; ATF4, activating transcription factor 4; ATF6, activating transcription factor 6; IREI $\alpha$, inositol-requiring enzyme I $\alpha$; XBPI-U, un-spliced X-box-binding protein I; XBPI-S, spliced X-box-binding protein I; EpFAs, epoxide fatty acids; UPR, unfolded protein response. 
However, there is no research about the interaction of these signaling pathways in pain research, illustrating additional studies are needed to explore the link between these signaling pathways in the pain biology and the putative role of EpFAs.

\section{Preclinical Research and Clinical Trials of sEHIs}

Currently, several preclinical studies are evaluating the effects of sEHIs in the pain management in animals. TPPU, an potent sEHI, has multimodal analgesics effects in a rat chronic pain model without changing the motor control and functioning in control animals. ${ }^{113}$ There are also several reports evaluating the sEHIs in the pain management in veterinary medicine. In a chronic laminitic horses, sEH activity in the digital laminae is significantly higher $(P=0.01)$ than in healthy horses, ${ }^{114}$ and treatment with the sEHI $t$-TUCB for 10 days significantly reduced the forelimb lifts and the pain scores compared with baseline $(P=0.04){ }^{114}$ A follow-up study showed that no adverse effects were detected on clinical and laboratory examinations during and after $t$-TUCB administration. No new episodes of laminitis have been noted up to the 120 days following treatment. ${ }^{115}$ Consistent with these studies, in another randomized controlled trial which used LPSinduced inflammatory joint pain in adult mares, treatment of $1 \mathrm{mg} / \mathrm{kg} t$-TUCB lowered the pain, lameness and tactile allodynia, further demonstrating the analgesia effect of $t$-TUCB. ${ }^{116}$ Additionally, administration of $t$-TUCB orally for five days significantly reduced pain at a dose of $5 \mathrm{mg} /$ $\mathrm{kg}$ in aged dogs with natural arthritis. ${ }^{117}$ Together, sEHI have already shown efficacy for inflammatory and neuropathic pain in rodents, with no apparent adverse or addictive effects, as well as relieving natural-onset pathological pain in horses and dogs (Table 1). Since horses and dogs are sensitive to side effects of NSAIDs and COXIBs, the well-established synergism of $\mathrm{sEH}$ inhibitors with these drugs and their reduction of side effects offers an attractive drug combination in veterinary medicine.

In human, 1-(1-acetypiperidin-4-yl)-3-adamantanylurea (APAU), a potent and selective sEHI, has been in clinical development targeting hypertension and type 2 diabetes, and was well tolerated, no dose-related adverse events were observed during either study in healthy subjects. ${ }^{118}$ The sEHI GSK2256294 (chemical name: 1R,3S)- $N$-[[4-cyano2-(trifluoromethyl)phenyl]methyl]-3-[[4-methyl-6-(methylamino)-1,3,5-triazin-2-yl]amino]-cyclohexanecarboxamide was well-tolerated and demonstrated sustained inhibition of sEH activity on COPD human patients. ${ }^{119}$ Recently a new class of oral non-narcotic analgesics based on inhibition of the sEH, EC5026 (chemical name: (S)-1-[3-fluoro-4-(trifluoromethoxy)phenyl]-3-\{1-(2-methylbutanoyl] piperidin-

Table I Preclinical Studies of Soluble Epoxide Hydrolase Inhibitors in Pain Model

\begin{tabular}{|c|c|c|c|c|c|c|}
\hline No. & Seh Inhibitor & Species & Routes & Dose & Model & Reference \\
\hline 1 & TPPU & Rat & Oral gavage & $3 \mathrm{mg} / \mathrm{kg}$ & Streptozocin induced neuropathic pain model & Wagner et al. $2020^{113}$ \\
\hline 2 & $t-T \cup C B$ & Horse & Intravenously & $0.1 \mathrm{mg} / \mathrm{kg}$ & Chronic laminitis & Guedes et al. $2017^{114}$ \\
\hline 3 & $t$-TUCB & Mares & Intravenously & $1 \mathrm{mg} / \mathrm{kg}$ & LPS-indued inflammatory radiocarpal synovitis & Guedes et al $.2018^{116}$ \\
\hline 4 & $t$-TUCB & Dogs & Orally & $5 \mathrm{mg} / \mathrm{kg}$ & Canine osteoarthritis & McReynolds et al. $2019^{117}$ \\
\hline
\end{tabular}


4-yl \}urea), has finished the Phase 1a clinical trial, showing no adverse effect on healthy volunteers. ${ }^{120}$ EC5026 is developed to treat neuropathic pain and should enter a Phase 2 clinical trial soon.

\section{Conclusion}

Currently, a large population in the US suffer with chronic pain, due to lack of efficacy, high expense, and safety problems, making chronic pain a serious health problem. It is important to identify novel therapeutic targets for chronic pain, to develop effective and safe methods for chronic pain treatment. Substantial studies have shown the EpFAs play essential roles in the pathology of inflammation and chronic pain, and our review further discusses the underlying molecular mechanisms of EpFAs/sEHI actions as an analgesic strategy for pain management. Recently several clinical trials of $\mathrm{sEH}$ inhibitors aiming at different diseases including chronic pain, hypertension, and COPD, emphasizing the importance of $\mathrm{sEH}$ as a promising therapeutic target. While more mechanisms need to be explored, inhibition of sEH to stabilize the beneficial effect of EpFAs is a potent and safe approach for pain management.

\section{Acknowledgments}

This study was supported, in part, by a grant from the National Institute of Environmental Health Sciences (NIEHS) Grant R35ES030443, and NIEHS Superfund Research Program P42 ES004699.

\section{Disclosure}

Karen M Wagner reports personal fees from EicOsis LLC, outside the submitted work. Christophe Morisseau reports grants from NIEHS, outside the submitted work. The University of California holds patents on the use of $\mathrm{sEH}$ inhibitors to treat inflammation, inflammatory pain, and neuropathic pain. Bruce D Hammock is a cofounder and Karen M Wagner is an employee of EicOsis L.L.C., a startup company advancing sEH inhibitors into the clinic. The authors report no other potential conflicts of interest in this work.

\section{References}

1. Mills SEE, Nicolson KP, Smith BH. Chronic pain: a review of its epidemiology and associated factors in population-based studies. $\mathrm{Br} J$ Anaesth. 2019;123(2):e273-e283. doi:10.1016/j.bja.2019.03.023

2. Lumley MA, Cohen JL, Borszcz GS, et al. Pain and emotion: a biopsychosocial review of recent research. J Clin Psychol. 2011;67 (9):942-968. doi:10.1002/jclp.20816

3. Gaskin DJ, Richard P. The economic costs of pain in the United States. J Pain. 2012;13(8):715-724. doi:10.1016/j.jpain.2012.03.009
4. Dahlhamer J, Lucas J, Zelaya C, et al. Prevalence of chronic pain and high-impact chronic pain among adults - United States, 2016. MMWR Morb Mortal Wkly Rep. 2018;67(36):1001-1006. doi:10.15585/mmwr.mm6736a2

5. Avril T, Chevet E. Stress signaling in pain control. Science. 2019;365(6450):224-225. doi:10.1126/science.aay2721

6. Kerns RD, Krebs EE, Atkins D. Making integrated multimodal pain care a reality: a path forward. J Gen Intern Med. 2018;33 (Suppl 1):1-3. doi:10.1007/s11606-018-4361-6

7. Millan MJ. The induction of pain: an integrative review. Prog Neurobiol. 1999;57(1):1-164. doi:10.1016/s0301-0082(98)00 048-3

8. Finnerup NB, Ropper AH. Nonnarcotic methods of pain management. $N$ Engl J Med. 2019;380(25):2440-2448. doi:10.1056/ NEJMra1807061

9. Orr PM, Shank BC, Black AC. The role of pain classification systems in pain management. Crit Care Nurs Clin North Am. 2017;29(4):407-418. doi:10.1016/j.cnc.2017.08.002

10. Dubin AE, Patapoutian A. Nociceptors: the sensors of the pain pathway. J Clin Invest. 2010;120(11):3760-3772. doi:10.1172/ JCI42843

11. Treede RD, Rief W, Barke A, et al. Chronic pain as a symptom or a disease: the IASP classification of chronic pain for the international classification of diseases (ICD-11). Pain. 2019;160(1):1927. doi:10.1097/j.pain.0000000000001384

12. Vasko MR. Inflammatory pain. In: Binder MD, Hirokawa N, Windhorst U, editors. Encyclopedia of Neuroscience. Springer Berlin Heidelberg; 2009:1952-1955.

13. Wang Y, Wang W, Sanidad KZ, Shih PA, Zhao X, Zhang G. Eicosanoid signaling in carcinogenesis of colorectal cancer. Cancer Metastasis Rev. 2018;37(2-3):257-267. doi:10.1007/ s10555-018-9739-8

14. Dennis EA, Norris PC. Eicosanoid storm in infection and inflammation. Nat Rev Immunol. 2015;15(8):511-523. doi:10.1038/ nri3859

15. Petho G, Reeh PW. Sensory and signaling mechanisms of bradykinin, eicosanoids, platelet-activating factor, and nitric oxide in peripheral nociceptors. Physiol Rev. 2012;92(4):1699-1775. doi:10.1152/physrev.00048.2010

16. Zeldin DC. Epoxygenase pathways of arachidonic acid metabolism. J Biol Chem. 2001;276(39):36059-36062. doi:10.1074/jbc. R100030200

17. Funk CD. Prostaglandins and leukotrienes: advances in eicosanoid biology. Science. 2001;294(5548):1871-1875. doi:10.1126/ science.294.5548.1871

18. Brash AR. Lipoxygenases: occurrence, functions, catalysis, and acquisition of substrate. J Biol Chem. 1999;274(34):2367923682. doi:10.1074/jbc.274.34.23679

19. Sudhahar V, Shaw S, Imig JD. Epoxyeicosatrienoic acid analogs and vascular function. Curr Med Chem. 2010;17(12):1181-1190. doi:10.2174/092986710790827843

20. Panigrahy D, Greene ER, Pozzi A, Wang DW, Zeldin DC. EET signaling in cancer. Cancer Metastasis Rev. 2011;30(3-4):525540. doi:10.1007/s10555-011-9315-y

21. Spector AA, Norris AW. Action of epoxyeicosatrienoic acids on cellular function. Am J Physiol Cell Physiol. 2007;292(3):C9961012. doi:10.1152/ajpcell.00402.2006

22. Morisseau C, Inceoglu B, Schmelzer K, et al. Naturally occurring monoepoxides of eicosapentaenoic acid and docosahexaenoic acid are bioactive antihyperalgesic lipids. J Lipid Res. 2010;51 (12):3481-3490. doi:10.1194/jlr.M006007

23. Inceoglu B, Schmelzer KR, Morisseau C, Jinks SL, Hammock BD. Soluble epoxide hydrolase inhibition reveals novel biological functions of epoxyeicosatrienoic acids (EETs). Prostaglandins Other Lipid Mediat. 2007;82(1-4):42-49. doi:10.1016/j. prostaglandins.2006.05.004 
24. Wagner K, Inceoglu B, Gill SS, Hammock BD. Epoxygenated fatty acids and soluble epoxide hydrolase inhibition: novel mediators of pain reduction. J Agric Food Chem. 2011;59(7):28162824. doi: $10.1021 / \mathrm{jf} 102559 \mathrm{q}$

25. Wagner K, Inceoglu B, Hammock BD. Soluble epoxide hydrolase inhibition, epoxygenated fatty acids and nociception. Prostaglandins Other Lipid Mediat. 2011;96(1-4):76-83. doi:10.1016/j.prostaglandins.2011.08.001

26. Zhang G, Kodani S, Hammock BD. Stabilized epoxygenated fatty acids regulate inflammation, pain, angiogenesis and cancer. Prog Lipid Res. 2014;53:108-123. doi:10.1016/j.plipres.2013.11.003

27. Hendrickson BA, Gokhale R, Cho JH. Clinical aspects and pathophysiology of inflammatory bowel disease. Clin Microbiol Rev. 2002;15(1):79-94. doi:10.1128/cmr.15.1.79-94.2002

28. Imig JD, Hammock BD. Soluble epoxide hydrolase as a therapeutic target for cardiovascular diseases. Nat Rev Drug Discov. 2009;8(10):794-805. doi:10.1038/nrd2875

29. Morisseau C, Hammock BD. Impact of soluble epoxide hydrolase and epoxyeicosanoids on human health. Annu Rev Pharmacol Toxicol. 2013;53(1):37-58. doi:10.1146/annurev-pharmtox-011112-140244

30. Zhang W, Li H, Dong H, Liao J, Hammock BD, Yang GY. Soluble epoxide hydrolase deficiency inhibits dextran sulfate sodium-induced colitis and carcinogenesis in mice. Anticancer Res. 2013;33(12):5261-5271.

31. Wang W, Yang J, Zhang J, et al. Lipidomic profiling reveals soluble epoxide hydrolase as a therapeutic target of obesityinduced colonic inflammation. Proc Natl Acad Sci U S A. 2018;115(20):5283-5288. doi:10.1073/pnas.1721711115

32. Lopez-Vicario C, Alcaraz-Quiles J, Garcia-Alonso V, et al. Inhibition of soluble epoxide hydrolase modulates inflammation and autophagy in obese adipose tissue and liver: role for omega-3 epoxides. Proc Natl Acad Sci U S A. 2015;112(2):536-541. doi:10.1073/pnas.1422590112

33. Imig JD, Zhao X, Capdevila JH, Morisseau C, Hammock BD. Soluble epoxide hydrolase inhibition lowers arterial blood pressure in angiotensin II hypertension. Hypertension. 2002;39(2 Pt 2):690-694. doi:10.1161/hy0202.103788

34. Zimmer B, Angioni C, Osthues T, et al. The oxidized linoleic acid metabolite 12,13-DiHOME mediates thermal hyperalgesia during inflammatory pain. Biochim Biophys Acta. 2018;1863(7):669678. doi:10.1016/j.bbalip.2018.03.012

35. Wagner K, Inceoglu B, Dong H, et al. Comparative efficacy of 3 soluble epoxide hydrolase inhibitors in rat neuropathic and inflammatory pain models. Eur J Pharmacol. 2013;700(13):93-101. doi:10.1016/j.ejphar.2012.12.015

36. Wagner K, Yang J, Inceoglu B, Hammock BD. Soluble epoxide hydrolase inhibition is antinociceptive in a mouse model of diabetic neuropathy. J Pain. 2014;15(9):907-914. doi:10.1016/j. jpain.2014.05.008

37. Wagner K, Gilda J, Yang J, et al. Soluble epoxide hydrolase inhibition alleviates neuropathy in Akita (Ins2 Akita) mice. Behav Brain Res. 2017;326:69-76. doi:10.1016/j.bbr.2017.02.048

38. Schmelzer KR, Inceoglu B, Kubala L, et al. Enhancement of antinociception by coadministration of nonsteroidal anti-inflammatory drugs and soluble epoxide hydrolase inhibitors. Proc Natl Acad Sci U S A. 2006;103(37):13646-13651. doi:10.1073/pnas.0605908103

39. Graham DJ. COX-2 inhibitors, other NSAIDs, and cardiovascular risk: the seduction of common sense. JAMA. 2006;296(13):16531656. doi:10.1001/jama.296.13.jed60058

40. Sostres C, Gargallo CJ, Arroyo MT, Lanas A. Adverse effects of non-steroidal anti-inflammatory drugs (NSAIDs, aspirin and coxibs) on upper gastrointestinal tract. Best Pract Res Clin Gastroenterol. 2010;24(2):121-132. doi:10.1016/j.bpg.2009.11.005

41. Hwang SH, Wagner KM, Morisseau C, et al. Synthesis and structureactivity relationship studies of urea-containing pyrazoles as dual inhibitors of cyclooxygenase-2 and soluble epoxide hydrolase. $J$ Med Chem. 2011;54(8):3037-3050. doi:10.1021/jm2001376
42. Sasso O, Wagner K, Morisseau C, Inceoglu B, Hammock BD, Piomelli D. Peripheral FAAH and soluble epoxide hydrolase inhibitors are synergistically antinociceptive. Pharmacol Res. 2015;97:7-15. doi:10.1016/j.phrs.2015.04.001

43. Kumar N, Goldminz AM, Kim N, Gottlieb AB. Phosphodiesterase 4-targeted treatments for autoimmune diseases. BMC Med. 2013;11(1):96. doi:10.1186/1741-7015-11-96

44. Inceoglu B, Wagner K, Schebb NH, et al. Analgesia mediated by soluble epoxide hydrolase inhibitors is dependent on cAMP. Proc Natl Acad Sci U S A. 2011;108(12):5093-5097. doi:10.1073/ pnas. 1101073108

45. Blocher R, Wagner KM, Gopireddy RR, et al. Orally available soluble epoxide hydrolase/phosphodiesterase 4 dual inhibitor treats inflammatory pain. $J$ Med Chem. 2018;61(8):3541-3550. doi:10.1021/acs.jmedchem.7b01804

46. Sutherland EW, Rall TW. Fractionation and characterization of a cyclic adenine ribonucleotide formed by tissue particles. $J$ Biol Chem. 1958;232(2):1077-1091.

47. Steuer Costa W, Yu SC, Liewald JF, Gottschalk A. Fast cAMP modulation of neurotransmission via neuropeptide signals and vesicle loading. Curr Biol. 2017;27(4):495-507. doi:10.1016/j. cub.2016.12.055

48. Aronica SM, Kraus WL, Katzenellenbogen BS. Estrogen action via the cAMP signaling pathway: stimulation of adenylate cyclase and cAMP-regulated gene transcription. Proc Natl Acad Sci U S A. 1994;91(18):8517-8521. doi:10.1073/pnas.91.18.8517

49. Raker VK, Becker C, Steinbrink K. The cAMP pathway as therapeutic target in autoimmune and inflammatory diseases. Front Immunol. 2016;7:123. doi:10.3389/fimmu.2016.00123

50. Conti M, Beavo J. Biochemistry and physiology of cyclic nucleotide phosphodiesterases: essential components in cyclic nucleotide signaling. Annu Rev Biochem. 2007;76:481-511. doi:10.1146/annurev.biochem.76.060305.150444

51. Knott EP, Assi M, Rao SN, Ghosh M, Pearse DD. Phosphodiesterase inhibitors as a therapeutic approach to neuroprotection and repair. Int J Mol Sci. 2017;18(4). doi:10.3390/ ijms 18040696

52. Feneck R. Phosphodiesterase inhibitors and the cardiovascular system. Contin Educ Anaesth Crit Care Pain. 2008;8(2):76. doi:10.1093/bjaceaccp/mkn010

53. Kumar A, Jain NK, Kulkarni SK. Analgesic and anti-inflammatory effects of phosphodiesterase inhibitors. Indian J Exp Biol. 2000;38(1):26-30.

54. Inceoglu B, Jinks SL, Ulu A, et al. Soluble epoxide hydrolase and epoxyeicosatrienoic acids modulate two distinct analgesic pathways. Proc Natl Acad Sci U S A. 2008;105(48):18901-18906. doi:10.1073/pnas.0809765105

55. Evans RM, Barish GD, Wang YX. PPARs and the complex journey to obesity. Nat Med. 2004;10(4):355-361. doi:10.1038/ $\mathrm{nm} 1025$

56. Ahmadian M, Suh JM, Hah N, et al. PPARgamma signaling and metabolism: the good, the bad and the future. Nat Med. 2013;19 (5):557-566. doi:10.1038/nm.3159

57. Youssef J, Badr M. Peroxisome proliferator-activated receptors and cancer: challenges and opportunities. $\mathrm{Br} J$ Pharmacol. 2011;164(1):68-82. doi:10.1111/j.1476-5381.2011.01383.x

58. Churi SB, Abdel-Aleem OS, Tumber KK, Scuderi-Porter H, Taylor BK. Intrathecal rosiglitazone acts at peroxisome proliferator-activated receptor-gamma to rapidly inhibit neuropathic pain in rats. $J$ Pain. 2008;9(7):639-649. doi:10.1016/j.jpain.2008.02.002

59. Costa B, Comelli F, Bettoni I, Colleoni M, Giagnoni G. The endogenous fatty acid amide, palmitoylethanolamide, has antiallodynic and anti-hyperalgesic effects in a murine model of neuropathic pain: involvement of $\mathrm{CB}(1)$, TRPV1 and PPARgamma receptors and neurotrophic factors. Pain. 2008;139 (3):541-550. doi:10.1016/j.pain.2008.06.003 
60. Lazennec G, Canaple L, Saugy D, Wahli W. Activation of peroxisome proliferator-activated receptors (PPARs) by their ligands and protein kinase A activators. Mol Endocrinol. 2000;14 (12):1962-1975. doi:10.1210/mend.14.12.0575

61. Lim H, Dey SK. A novel pathway of prostacyclin signalinghanging out with nuclear receptors. Endocrinology. 2002;143 (9):3207-3210. doi:10.1210/en.2002-220159

62. Benani A, Heurtaux T, Netter P, Minn A. Activation of peroxisome proliferator-activated receptor alpha in rat spinal cord after peripheral noxious stimulation. Neurosci Lett. 2004;369(1):59 63. doi:10.1016/j.neulet.2004.07.056

63. LoVerme J, Russo R, La Rana G, et al. Rapid broad-spectrum analgesia through activation of peroxisome proliferator-activated receptor-alpha. J Pharmacol Exp Ther. 2006;319(3):1051-1061. doi:10.1124/jpet.106.111385

64. Ruiz-Medina J, Flores JA, Tasset I, Tunez I, Valverde O, Fernandez-Espejo E. Alteration of neuropathic and visceral pain in female C57BL/6J mice lacking the PPAR-alpha gene. Psychopharmacology (Berl). 2012;222(3):477-488. doi:10.1007/ s00213-012-2662-8

65. Devchand PR, Keller H, Peters JM, Vazquez M, Gonzalez FJ, Wahli W. The PPARalpha-leukotriene B4 pathway to inflammation control. Nature. 1996;384(6604):39-43. doi:10.1038/ $384039 \mathrm{a} 0$

66. Corona JC, Duchen MR. PPARgamma as a therapeutic target to rescue mitochondrial function in neurological disease. Free Radic Biol Med. 2016;100:153-163. doi:10.1016/j.freeradbiomed.2016.06.023

67. Dello Russo C, Gavrilyuk V, Weinberg G, et al. Peroxisome proliferator-activated receptor gamma thiazolidinedione agonists increase glucose metabolism in astrocytes. J Biol Chem. 2003;278 (8):5828-5836. doi:10.1074/jbc.M208132200

68. Lopez-Armada MJ, Riveiro-Naveira RR, Vaamonde-Garcia C, Valcarcel-Ares MN. Mitochondrial dysfunction and the inflammatory response. Mitochondrion. 2013;13(2):106-118. doi:10.1016/j.mito.2013.01.003

69. Hasegawa-Moriyama M, Kurimoto $T$, Nakama $M$, et al. Peroxisome proliferator-activated receptor-gamma agonist rosiglitazone attenuates inflammatory pain through the induction of heme oxygenase-1 in macrophages. Pain. 2013;154(8):14021412. doi:10.1016/j.pain.2013.04.039

70. De Taeye BM, Morisseau C, Coyle J, et al. Expression and regulation of soluble epoxide hydrolase in adipose tissue. Obesity (Silver Spring). 2010;18(3):489-498. doi:10.1038/ oby.2009.227

71. Pang W, Li N, Ai D, Niu XL, Guan YF, Zhu Y. Activation of peroxisome proliferator-activated receptor-gamma downregulates soluble epoxide hydrolase in cardiomyocytes. Clin Exp Pharmacol Physiol. 2011;38(6):358-364. doi:10.1111/j.14401681.2011.05492.x

72. Hiesinger K, Wagner KM, Hammock BD, Proschak E, Hwang SH. Development of multitarget agents possessing soluble epoxide hydrolase inhibitory activity. Prostaglandins Other Lipid Mediat. 2019;140:31-39. doi:10.1016/j.prostaglandins.2018.12.003

73. Liu Y, Zhang Y, Schmelzer K, et al. The antiinflammatory effect of laminar flow: the role of PPARgamma, epoxyeicosatrienoic acids, and soluble epoxide hydrolase. Proc Natl Acad Sci $U \quad S \quad$ A. 2005;102(46):16747-16752. doi:10.1073/ pnas.0508081102

74. Hye Khan MA, Kolb L, Skibba M, et al. A novel dual PPARgamma agonist/sEH inhibitor treats diabetic complications in a rat model of type 2 diabetes. Diabetologia. 2018;61(10):2235-2246. doi:10.1007/s00125-018-4685-0

75. Khan AH, Stavniichuk A, Yeboah MM, et al. A dual soluble epoxide hydrolase inhibitor/PPAR- $\gamma$ agonist prevents renal fibrosis in mouse unilateral ureteral obstruction model. FASEB J. 2019;33(1_supplement):678.12. doi:10.1096/fasebj.2019.33.1_supplement.678.12
76. Ota K, Hammock B. Cytosolic and microsomal epoxide hydrolases: differential properties in mammalian liver. Science. 1980;207(4438):1479-1481. doi:10.1126/science.7361100

77. Kim J, Yoon SP, Toews ML, et al. Pharmacological inhibition of soluble epoxide hydrolase prevents renal interstitial fibrogenesis in obstructive nephropathy. Am J Physiol Renal Physiol. 2015;308 (2):F131-9. doi:10.1152/ajprenal.00531.2014

78. Venkatachalam K, Montell C. TRP channels. Annu Rev Biochem. 2007;76(1):387-417. doi:10.1146/annurev. biochem.75.103004.142819

79. Nilius B, Owsianik G. The transient receptor potential family of ion channels. Genome Biol. 2011;12(3):218. doi:10.1186/gb2011-12-3-218

80. da Costa DS, Meotti FC, Andrade EL, Leal PC, Motta EM, Calixto JB. The involvement of the transient receptor potential A1 (TRPA1) in the maintenance of mechanical and cold hyperalgesia in persistent inflammation. Pain. 2010;148(3):431-437. doi:10.1016/j.pain.2009.12.002

81. Story GM, Peier AM, Reeve AJ, et al. ANKTM1, a TRP-like channel expressed in nociceptive neurons, is activated by cold temperatures. Cell. 2003;112(6):819-829. doi:10.1016/s00928674(03)00158-2

82. Jordt SE, Bautista DM, Chuang HH, et al. Mustard oils and cannabinoids excite sensory nerve fibres through the TRP channel ANKTM1. Nature. 2004;427(6971):260-265. doi:10.1038/nature02282

83. Koivisto A, Jalava N, Bratty R, Pertovaara A. TRPA1 antagonists for pain relief. Pharmaceuticals. 2018;11(4):117. doi:10.3390/ ph11040117

84. Nassini R, Materazzi S, Benemei S, Geppetti P. The TRPA1 channel in inflammatory and neuropathic pain and migraine. Rev Physiol Biochem Pharmacol. 2014;167:1-43. doi:10.1007/112_2014_18

85. Trevisan G, Benemei S, Materazzi S, et al. TRPA1 mediates trigeminal neuropathic pain in mice downstream of monocytes/ macrophages and oxidative stress. Brain. 2016;139(Pt5):13611377. doi:10.1093/brain/aww038

86. Jara-Oseguera A, Simon SA, Rosenbaum T. TRPV1: on the road to pain relief. Curr Mol Pharmacol. 2008;1(3):255-269. doi:10.2174/1874467210801030255

87. Premkumar LS, Sikand P. TRPV1: a target for next generation analgesics. Curr Neuropharmacol. 2008;6(2):151-163. doi:10.2174/157015908784533888

88. Caterina MJ, Leffler A, Malmberg AB, et al. Impaired nociception and pain sensation in mice lacking the capsaicin receptor. Science. 2000;288(5464):306-313. doi:10.1126/science.288.5464.306

89. Iida T, Shimizu I, Nealen ML, Campbell A, Caterina M. Attenuated fever response in mice lacking TRPV1. Neurosci Lett. 2005;378(1):28-33. doi:10.1016/j.neulet.2004.12.007

90. Manitpisitkul P, Brandt M, Flores CM, et al. TRPV1 antagonist JNJ-39439335 (mavatrep) demonstrates proof of pharmacology in healthy men: a first-in-human, double-blind, placebo-controlled, randomized, sequential group study. Pain Rep. 2016;1(4):e576. doi:10.1097/PR9.0000000000000576

91. Arsenault P, Chiche D, Brown W, et al. NEO6860, modalityselective TRPV1 antagonist: a randomized, controlled, proof-ofconcept trial in patients with osteoarthritis knee pain. Pain Rep. 2018;3(6):e696. doi:10.1097/PR9.0000000000000696

92. Garami A, Shimansky YP, Rumbus Z, et al. Hyperthermia induced by transient receptor potential vanilloid-1 (TRPV1) antagonists in human clinical trials: insights from mathematical modeling and meta-analysis. Pharmacol Ther. 2020;208:107474. doi:10.1016/j.pharmthera.2020.107474

93. Iliff JJ, Fairbanks SL, Balkowiec A, Alkayed NJ. Epoxyeicosatrienoic acids are endogenous regulators of vasoactive neuropeptide release from trigeminal ganglion neurons. $J$ Neurochem. 2010;115(6):1530-1542. doi:10.1111/j.1471-4159. 2010.07059.x 
94. Kadowaki H, Nishitoh H. Signaling pathways from the endoplasmic reticulum and their roles in disease. Genes (Basel). 2013;4 (3):306-333. doi:10.3390/genes4030306

95. Sano R, Reed JC. ER stress-induced cell death mechanisms. Biochim Biophys Acta. 2013;1833(12):3460-3470. doi:10.1016/ j.bbamcr.2013.06.028

96. Bravo R, Parra V, Gatica D, et al. Endoplasmic reticulum and the unfolded protein response: dynamics and metabolic integration. Int Rev Cell Mol Biol. 2013;301:215-290. doi:10.1016/B978-012-407704-1.00005-1

97. Zhang E, Yi MH, Shin N, et al. Endoplasmic reticulum stress impairment in the spinal dorsal horn of a neuropathic pain model. Sci Rep. 2015;5(1):11555. doi:10.1038/srep11555

98. Oakes SA, Papa FR. The role of endoplasmic reticulum stress in human pathology. Annu Rev Pathol. 2015;10(1):173-194. doi:10.1146/annurev-pathol-012513-104649

99. Xu C, Bailly-Maitre B, Reed JC. Endoplasmic reticulum stress: cell life and death decisions. J Clin Invest. 2005;115(10):26562664. doi: $10.1172 /$ JCI26373

100. Chopra S, Giovanelli P, Alvarado-Vazquez PA, et al. IRE1alpha-XBP1 signaling in leukocytes controls prostaglandin biosynthesis and pain. Science. 2019;365(6450):eaau6499. doi:10.1126/science.aau6499

101. Yao W, Yang X, Zhu J, Gao B, Shi H, Xu L. IRE1alpha siRNA relieves endoplasmic reticulum stress-induced apoptosis and alleviates diabetic peripheral neuropathy in vivo and in vitro. Sci Rep. 2018;8(1):2579. doi:10.1038/s41598-018-20950-9

102. Cameron NE. Role of endoplasmic reticulum stress in diabetic neuropathy. Diabetes. 2013;62(3):696-697. doi:10.2337/db12-1469

103. Lupachyk S, Watcho P, Stavniichuk R, Shevalye H, Obrosova IG. Endoplasmic reticulum stress plays a key role in the pathogenesis of diabetic peripheral neuropathy. Diabetes. 2013;62(3):944-952. doi:10.2337/db12-0716

104. Oyadomari S, Mori M. Roles of CHOP/GADD153 in endoplasmic reticulum stress. Cell Death Differ. 2004;11(4):381-389. doi:10.1038/sj.cdd.4401373

105. Bettaieb A, Nagata N, AbouBechara D, et al. Soluble epoxide hydrolase deficiency or inhibition attenuates diet-induced endoplasmic reticulum stress in liver and adipose tissue. $J$ Biol Chem. 2013;288(20):14189-14199. doi:10.1074/jbc.M113.458414

106. Jiang XS, Xiang XY, Chen XM, et al. Inhibition of soluble epoxide hydrolase attenuates renal tubular mitochondrial dysfunction and ER stress by restoring autophagic flux in diabetic nephropathy. Cell Death Dis. 2020;11(5):385. doi:10.1038/s41419-020-2594-x

107. Inceoglu B, Bettaieb A, Haj FG, Gomes AV, Hammock BD. Modulation of mitochondrial dysfunction and endoplasmic reticulum stress are key mechanisms for the wide-ranging actions of epoxy fatty acids and soluble epoxide hydrolase inhibitors. Prostaglandins Other Lipid Mediat. 2017;133:68-78. doi:10.1016/j.prostaglandins.2017.08.003

108. Inceoglu B, Bettaieb A, Trindade da Silva CA, Lee KSS, Haj FG, Hammock BD. Endoplasmic reticulum stress in the peripheral nervous system is a significant driver of neuropathic pain. Proc Natl Acad Sci U S A. 2015;112(29):9082-9087. doi:10.1073/pnas.1510137112
109. Rose TE, Morisseau C, Liu JY, et al. 1-Aryl-3-(1-acylpiperidin-4yl)urea inhibitors of human and murine soluble epoxide hydrolase: structure-activity relationships, pharmacokinetics, and reduction of inflammatory pain. $J$ Med Chem. 2010;53 (19):7067-7075. doi:10.1021/jm100691c

110. Yuliana A, Daijo A, Jheng HF, et al. Endoplasmic reticulum stress impaired uncoupling protein 1 expression via the suppression of peroxisome proliferator-activated receptor gamma binding activity in mice beige adipocytes. Int $J$ Mol Sci. 2019;20(2):274. doi:10.3390/ijms20020274

111. Chen HY, Liu Q, Salter AM, Lomax MA. Synergism between cAMP and PPARgamma signalling in the initiation of UCP1 gene expression in HIB1B brown adipocytes. PPAR Res. 2013;2013:476049. doi:10.1155/2013/476049

112. Song YF, Hogstrand C, Wei CC, Wu K, Pan YX, Luo Z. Endoplasmic reticulum (ER) stress and cAMP/PKA pathway mediated Zn-induced hepatic lipolysis. Environ Pollut. 2017;228:256-264. doi:10.1016/j.envpol.2017.05.046

113. Wagner KM, Atone J, Hammock BD. Soluble epoxide hydrolase inhibitor mediated analgesia lacks tolerance in rat models. Brain Res. 2020;1728:146573. doi:10.1016/j.brainres.2019.146573

114. Guedes A, Galuppo L, Hood D, Hwang SH, Morisseau C, Hammock BD. Soluble epoxide hydrolase activity and pharmacologic inhibition in horses with chronic severe laminitis. Equine Vet J. 2017;49(3):345-351. doi:10.1111/evj.12603

115. Guedes AG, Morisseau C, Sole A, et al. Use of a soluble epoxide hydrolase inhibitor as an adjunctive analgesic in a horse with laminitis. Vet Anaesth Analg. 2013;40(4):440-448. doi:10.1111/vaa.12030

116. Guedes AGP, Aristizabal F, Sole A, et al. Pharmacokinetics and antinociceptive effects of the soluble epoxide hydrolase inhibitor t-TUCB in horses with experimentally induced radiocarpal synovitis. $J$ Vet Pharmacol Ther. 2018;41(2):230-238. doi:10.1111/jvp.12463

117. McReynolds CB, Hwang SH, Yang J, et al. Pharmaceutical effects of inhibiting the soluble epoxide hydrolase in canine osteoarthritis. Front Pharmacol. 2019;10:533. doi:10.3389/ fphar.2019.00533

118. Chen D, Whitcomb R, MacIntyre E, et al. Pharmacokinetics and pharmacodynamics of AR9281, an inhibitor of soluble epoxide hydrolase, in single- and multiple-dose studies in healthy human subjects. J Clin Pharmacol. 2012;52(3):319-328. doi:10.1177/ 0091270010397049

119. Lazaar AL, Yang L, Boardley RL, et al. Pharmacokinetics, pharmacodynamics and adverse event profile of GSK2256294, a novel soluble epoxide hydrolase inhibitor. $\mathrm{Br} J$ Clin Pharmacol. 2016;81(5):971-979. doi:10.1111/bcp.12855

120. NINDS EHHINIoNDaS. Safety, tolerability, and pharmacokinetics of oral EC5026 in healthy subjects. Available from: https://clinicaltrials.gov/ct2/show/NCT04228302?term $=$ EC5026\&draw=2\&rank=1. Accessed December 2, 2020.
Journal of Pain Research

\section{Publish your work in this journal}

The Journal of Pain Research is an international, peer reviewed, open access, online journal that welcomes laboratory and clinical findings in the fields of pain research and the prevention and management of pain. Original research, reviews, symposium reports, hypothesis formation and commentaries are all considered for publication. The manuscript management system is completely online and includes a very quick and fair peer-review system, which is all easy to use. Visit http:// www.dovepress.com/testimonials.php to read real quotes from published authors. 